\title{
Influence of grapefruit-, orange- and apple-juice consumption on urinary variables and risk of crystallization
}

\author{
Ruth Hönow*, Norbert Laube, Anke Schneider, Torsten Keßler and Albrecht Hesse \\ Division of Experimental Urology, Department of Urology, University of Bonn, Sigmund-Freud-Str 25, \\ D-53 105 Bonn, Germany
}

(Received 1 August 2002 - Revised 14 February 2003 - Accepted 24 March 2003)

\begin{abstract}
Alkalizing beverages are highly effective in preventing the recurrence of calcium oxalate (Ox), uric acid and cystine lithiasis. The aim of the present study was to evaluate the influence of grapefruit-juice and apple-juice consumption on the excretion of urinary variables and the risk of crystallization in comparison with orange juice. All investigations were carried out on nine healthy female subjects without any history of stone formation and aged 26-35 years. Each juice was tested in a $5 \mathrm{~d}$ study. During the study, the subjects received a standardized diet. Fluid intake of 2.75 litres was composed of 2.25 litres neutral mineral water, 0.4 litre coffee and $0 \cdot 1$ litre milk. On the fourth and fifth day 0.5 litre mineral water was partly substituted by 0.5 or 1.0 litre juice under investigation respectively. The influence on urinary variables was evaluated in $24 \mathrm{~h}$ urine samples. In addition, the BONN risk index of $\mathrm{CaOx}$, relative supersaturation (RS) $\mathrm{CaOx}$ crystallization was determined. Due to an increased $\mathrm{pH}$ value and an increased citric acid excretion after consumption of each juice, the $\mathrm{RS}_{\mathrm{CaOx}}$ decreased statistically significantly $(P<0.05)$ for grapefruit juice, but not significantly for orange and apple juice. The BONN risk index yielded a distinct decrease in the crystallization risk. We showed that both grapefruit juice and apple juice reduce the risk of $\mathrm{CaOx}$ stone formation at a magnitude comparable with the effects obtained from orange juice.
\end{abstract}

Grapefruit juice: Apple juice: Orange juice: Relative supersaturation: Alkalizing beverages: BONN risk index

A high fluid intake is the first general advice given to patients in the prevention of stone recurrence, irrespective of stone composition. An increase of fluid intake is associated with a reduced risk for kidney stone formation, reported by several authors (Curhan et al. 1996, 1998; Hesse et al. 1993; Hesse \& Siener 1997). Urine dilution causes a lowering of the concentration of constituent ions and thus a decrease of the super-saturation of the stoneforming salts. Depending on the stone composition, several fluids have been found to be suitable, e.g. mineral water, orange juice, apple juice, fruit and herbal teas (Vahlensieck, 1986; Hesse et al. 1993; Wabner \& Pak 1993). Alkalizing beverages such as orange juice are highly effective in the metaphylaxis of calcium oxalate (Ox), uric acid and cystine lithiasis.

Curhan et al. $(1996,1998)$ investigated the influence of beverages on the risk of kidney stone formation in two prospective studies. Their investigations resulted in the postulation of grapefruit juice and apple juice being riskincreasing beverages in respect to $\mathrm{CaOx}$ formation. Their results were based on an evaluation of questionnaires without any measurements of urinary composition. These results, however, cannot be understood without any further information about the changes in urinary composition.
Therefore, the results lead to the question: why does the ingestion of grapefruit juice causes an effect that is different from that of other juices with a high content of citric acid? There must be a constituent of grapefruit juice be responsible for this effect. To find an answer to this question some authors investigated the influence of grapefruit juice on urinary composition (Goldfarb \& Asplin, 2000, 2001; Trinchieri et al. 2002). Unfortunately these investigations did not lead to meaningful results. The present study was undertaken to overcome these shortcomings by evaluating the influence of grapefruit juice and apple juice on urinary composition and therefore on risk of crystallization. The effects of both juices were compared with those obtained from the ingestion of orange juice. All juices were tested on the same persons and under the same dietary conditions.

\section{Materials and methods \\ All investigations were carried out using nine female vol- unteers with no history of urolithiasis or other renal dis- order. The mean age was 29 (range 26-35) years. All subjects received a standardized diet formulated according to the dietary recommendations of the German Society of}


Nutrition (Deutsche Gesellschaft für Ernährung, 1996). The diet consisted of normal food items to ensure consistency of the investigation results. The same type and amount of food was consumed for $5 \mathrm{~d}(103.0 \mathrm{mg} \mathrm{Ox} / \mathrm{d})$. Sports were not permitted during the experimental phase. Volunteers were supplied with breakfast, and lunch, both were ingested in our hospital. The other foods and the collecting bottles were given with full instructions. Substitutions were not allowed.

Fluid intake of 2.75 litres was composed of 2.25 litres neutral mineral water, 0.4 litre coffee and 0.1 litre milk. On the loading days (fourth day 0.5 litre, fifth day 1.0 litre) mineral water was partly substituted for by the juice tested. For details of the composition of grapefruit, orange and apple juice see Table 1 . The subjects received juices with $100 \%$ fruit content and without any additives (grapefruit juice from 'master product', apple juice from 'master product' (Hamburger Warencenter, Hamburgh, Germany) and orange juice from Krings, Herrath).

The $24 \mathrm{~h}$ urine samples were divided in two portions after each voiding. One fraction was stored at $4^{\circ} \mathrm{C}$ without any preservation. This fraction was used for the determination of the urinary $\mathrm{pH}$ value and the BONN risk index (BRI; for details, see later). The other fraction was also stored at $4^{\circ} \mathrm{C}$ and mixed with $10 \mathrm{ml} \mathrm{HCl}(250 \mathrm{ml} / \mathrm{l})$ to preserve the urine. Urine samples were tested for the presence of blood and infection. Nitrite-positive and haematuric samples were discarded. In addition, volume, specific gravity (urinometer) and $\mathrm{pH}$ (potentiometer) were recorded. The analytical methods used had the following relative $\mathrm{CV}(\%)$ : $\mathrm{Na}, \mathrm{K}$, and $\mathrm{Ca}$ (flame photometry) $1 \cdot 3$; $\mathrm{Mg}$ (xylidyl-blue reaction) $0.3 ; \mathrm{NH}_{4}^{+}$(ion selective electrode) 1.5 ; chloride (coulomb metric titration) $2 \cdot 0$; inorganic phosphate (phosphate molybdate reaction) $<5$; inorganic sulfate (nephelometry) $<5$; creatinine (Jaffé reaction) 2.0; uric acid (uricase method) $<5$; citric acid (citrate lyase method) 1.6; oxalic acid (HPLC enzyme reactor method) 0.5 (Hesse et al. 1997; Hönow et al. 1997; Hesse \& Bach, 1982).

The relative supersaturation (RS) for $\mathrm{CaOx}$ was calculated using the EQUIL 2 program (Finlayson, 1977; Werness et al. 1985). The Wilcoxon matched-pairs signed-rank test, was used testing two matched samples (control and loading day) as a non-parametric test of significance. The significance level was set at $5 \%$.

The BRI were determined according to Laube et al. (2000). The BRI is a newly established method for $\mathrm{CaOx}$ crystallization risk determination from unprepared native

Table 1. Composition of the juices tested (mg/l)

\begin{tabular}{lccc}
\hline & Grapefruit juice & Apple juice & Orange juice \\
\hline $\mathrm{pH}$ value & $31 \cdot 1$ & $34 \cdot 3$ & $37 \cdot 2$ \\
$\mathrm{Na}$ & 115 & $<110$ & $<110$ \\
$\mathrm{~K}$ & 1127 & 1084 & 1638 \\
$\mathrm{Mg}$ & 79 & $50 \cdot 4$ & 81 \\
$\mathrm{Ca}$ & 80 & 48 & 124 \\
$\mathrm{Citric}$ acid & 14120 & 44 & 8972 \\
Ascorbic acid & 400 & 14 & 420 \\
Oxalic acid & 2 & 10 & 2 \\
\hline
\end{tabular}

urine samples (Laube et al. 2001, 2002). In a standardized experimental procedure, the BRI is derived from the initial urinary concentration of free ionized $\mathrm{Ca}\left(\mathrm{Ca}^{2+}\right)$ : amount of ammonium Ox which has to be titrated to that urine $\left(\mathrm{Ox}^{2-}\right)$ in order to induce a precipitation of $\mathrm{CaOx}$ salts, i.e. $\mathrm{BRI}=\mathrm{Ca}^{2+} / \mathrm{Ox}^{2-}$.

In the present study, $\mathrm{Ca}^{2+}$ was measured by ion-selective electrodes. The moment of crystallization was detected by a laser-probe device (MTS-Messtechnik Schwartz, Dusseldorf, Germany).

The advantage of the BRI in the evaluation of the crystallization risk is the fact that all urinary components contribute their individual effects, which may promote and/or inhibit both salt precipitation and/or particle aggregation in the experiment.

\section{Results}

The main results are reported in Table 2 . The volumes of the $24 \mathrm{~h}$ urine samples did not differ from day 3 to day 4 and 5 . This represents the standardization of the volunteers. The dosage of 0.5 litre (and 1.0 litre) orange juice leads to an alkalization of the $24 \mathrm{~h}$ urine, whereas only the 1.0 litre dosage of apple juice caused a significant increase of the $\mathrm{pH}$ value. Only a slight increase of $\mathrm{pH}$ value was observed after ingestion of 0.5 or 1.0 litre grapefruit juice. The differences were not statistically significant. The citric acid excretion increased statistically significantly $(P<0 \cdot 05)$ in all juices tested at both dosages. The increases of $\mathrm{pH}$ values and of the citric acid excretions are shown in Fig. 1. The Ox excretions did not change during experimental phase. The excretion of $\mathrm{Ca}$ was significantly lower $(P<0.05)$ after the ingestion of 0.5 litre orange juice and of 0.5 litre grapefruit juice. However, the differences could not be confirmed after the ingestion was elevated to 1.0 litre. The urinary $\mathrm{Mg}$ excretion increased only with 1.0 litre grapefruit juice. Uric acid excretion was not influenced after ingestion of any of the juices. On the basis of changed urinary composition there is a decrease in $\mathrm{RS}_{\mathrm{CaOx}}$ after ingestion of all juices. This finding was statistically significant $(P<0.05)$ only for grapefruit juice $(0.5$ litre $)$.

The BRI decreased after the intake of 1.0 litre orange juice by 0.5 units, after intake of 1.0 litre grapefruit juice by 0.4 units and after intake of 1.0 litre apple juice by 0.5 units. These decreases are significant $(P<0.01$ for grapefruit juice and $P<0.05$ for orange juice and apple juice). Results are reported in Fig. 2.

\section{Discussion}

Grapefruit juice and orange juice contain about $10 \mathrm{mg}$ citric acid/g. The high content of citric acid causes an increased citric acid excretion and is responsible for the alkalizing effect. The elevated citric acid excretion due to the ingestion of apple juice, however, was unexpected and cannot be explained at the moment. The alkalizing effect and the increased citric acid excretion lead to a decreased $\mathrm{RS}_{\mathrm{CaOx}}$ and may have mainly caused the decreasing of the BRI values.

These results are in accordance with the results reported for orange juice by Wabner \& Pak (1993). However, these 
results are different from those reported by Curhan et al. (1996, 1998). They found an increasing risk of stone formation for a daily intake of $240 \mathrm{ml}$ grapefruit juice or apple juice. Apple juice intake was correlated directly with stone formation only for men, and not for women. It should be notified that they did not analyse any urinary variables or lithogenic constituents.

Goldfarb \& Coe (1999) postulated that grapefruit juice, if it stimulates stone formation, must have a significant effect on urinary composition different from that other citrus juices, or that the measurement of urinary composition in short-term studies fail to predict long-term outcomes accurately.

Goldfarb \& Asplin (2001) determined in urine the upper limits of metastability, based on a modified crystallization experiment described by Nicar et al. (1983). For that purpose, each urine sample was centrifuged, $\mathrm{pH}$ adjusted and then preserved with sodium acide. After this preparation, a crystallization experiment on these strongly altered urine samples was performed in order to obtain metastability.

It is clear that the metastability results cannot reflect the urinary situation in total. The BRI, however, takes into account the effects of all urinary constituents in their native ratio and native chemical environment: only unprepared urine samples are investigated. In urine compositions in which those substances not considered by metastability determination contribute a 'non-average' effect to the total crystal formation risk, the result of metastability cannot sufficiently reflect that situation as well as the BRI does. Only full consideration of all urinary substances, in particular of the macromolecular constituents that may have strong effects on the stone formation processes, allows reflection of all grapefruit-related influences on urinary composition, including those influences that are still unknown.

Changes in $\mathrm{RS}_{\mathrm{CaOx}}$ reliably reflect changes in the composition of the major urinary constituents. Goldfarb's investigations (Goldfarb \& Coe, 1999; Goldfarb \& Asplin, 2000, 2001) and our present results revealed only small effects of grapefruit juice on urinary $\mathrm{RS}_{\mathrm{CaOx}}$. This is mainly caused by small changes in urinary $\mathrm{pH}$ and citric acid concentrations after grapefruit ingestion.

Grapefruit juice is well known to increase the absorption of many drugs (Weber et al. 1996; Ameer \& Weintraub, 1997). Many studies have shown that the substance naringin (one of the main flavonoids), through its inhibitory effects on the cytochrome P450 enzymes, is responsible for the grapefruit-drug interactions (Fuhr \& Kummert, 1995). It has to be investigated in what way substances that appear through a delayed metabolism in the urine have an influence on the crystallization. The Ox excretion will not be influenced through the inhibition of the cytochrome P450 enzyme. This was confirmed also by the results of the present study.

The influence of grapefruit contents themselves on the crystallization has not been examined until now. However, naringin is excreted unchanged only in small quantities. Naringin appeared in urine $(5-57 \%)$ after a median lag time of $2 \mathrm{~h}$ as naringenin glucuronides (Fuhr \& Kummert, 1995). 
(a)

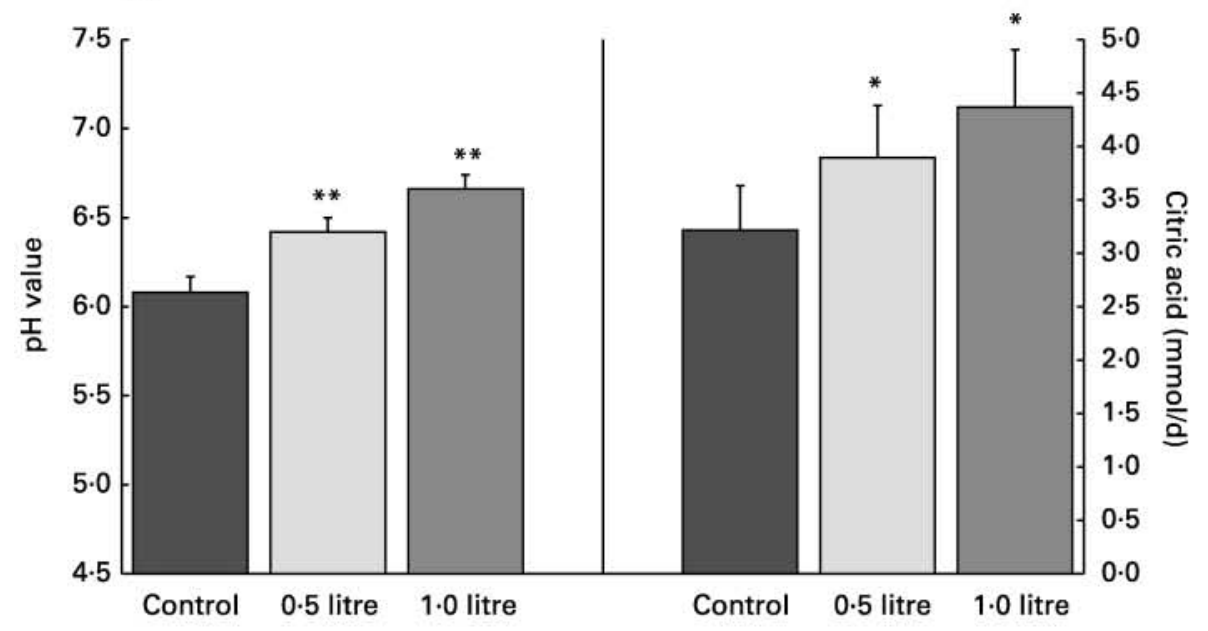

(b)

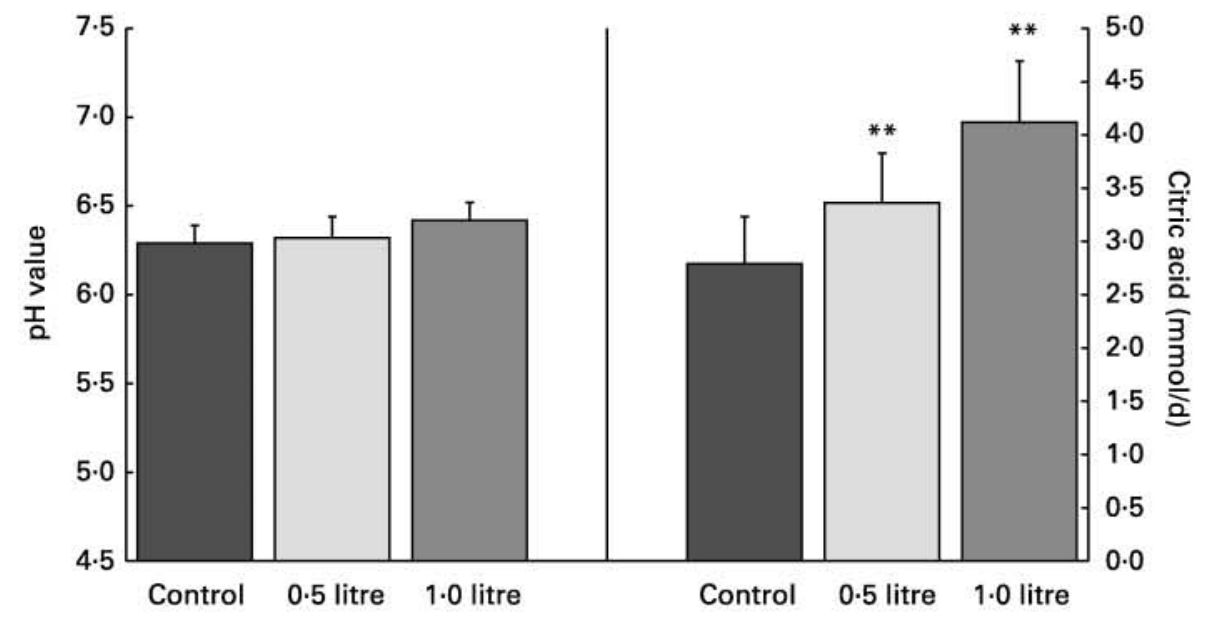

(c)

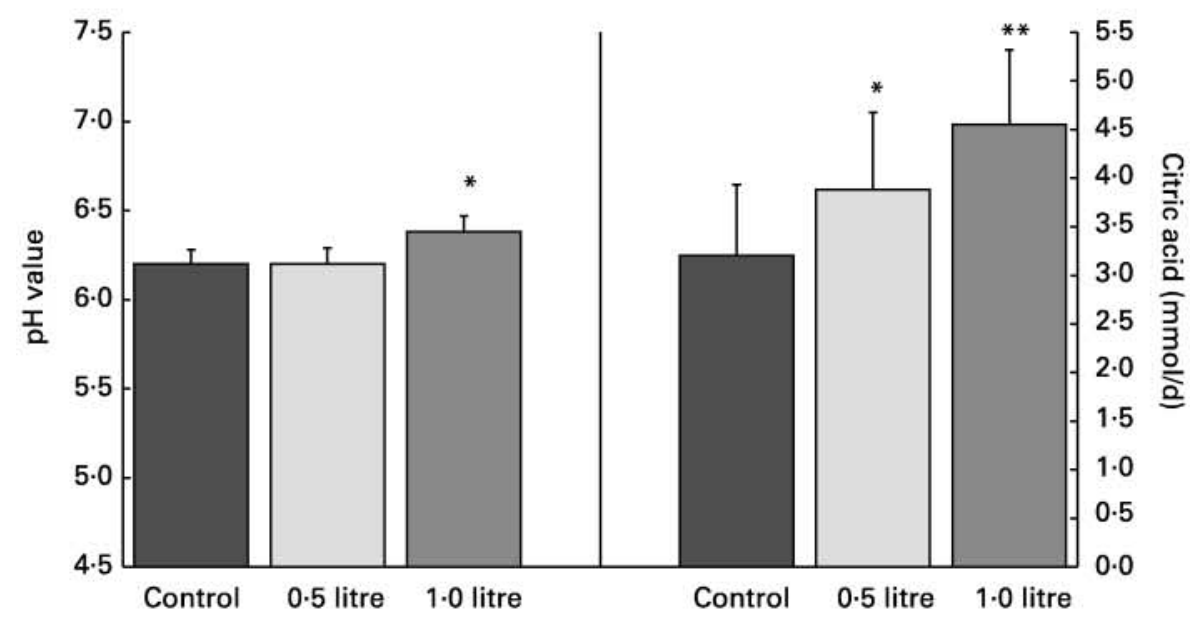

Fig. 1. Effect of orange juice (a), grapefruit juice (b) or apple juice (c) on urine pH value and citrate excretion. For details of fruit juices, subjects and procedures, see Table 1 and pp. 295-296. Values are means with their standard errors shown by vertical bars ( $n$ 9). Mean values were significantly different from those of the control: ${ }^{\star} P<0.05,{ }^{\star \star} P<0.01$. 
(a)

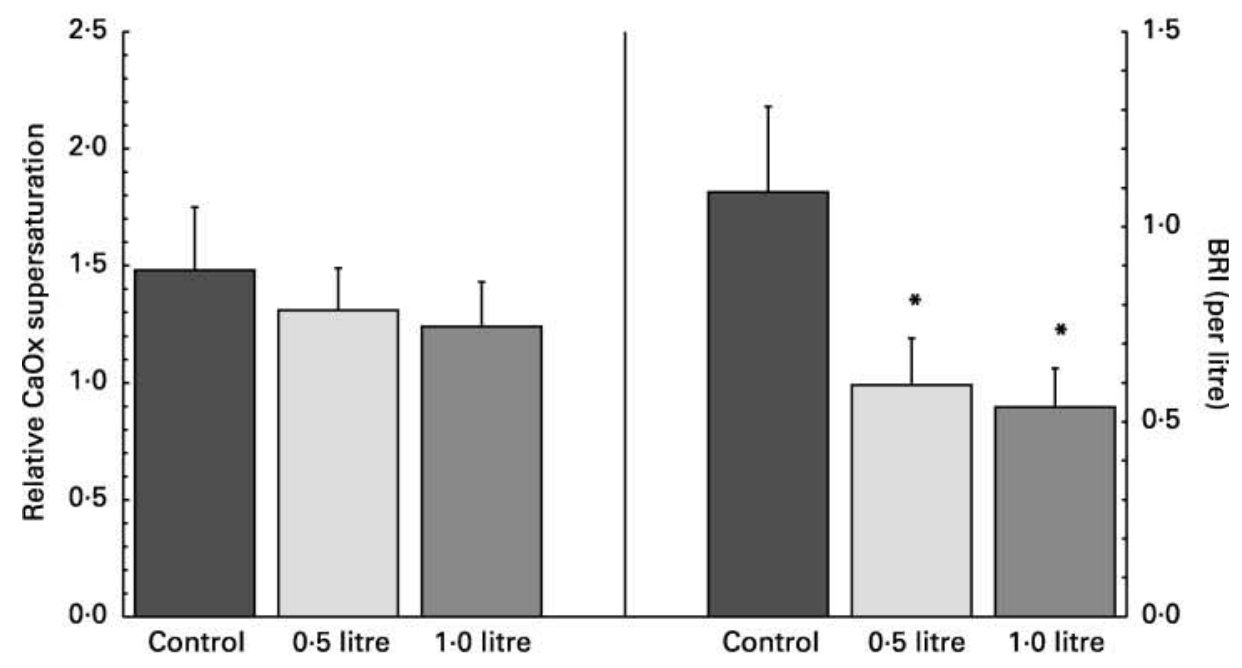

(b)

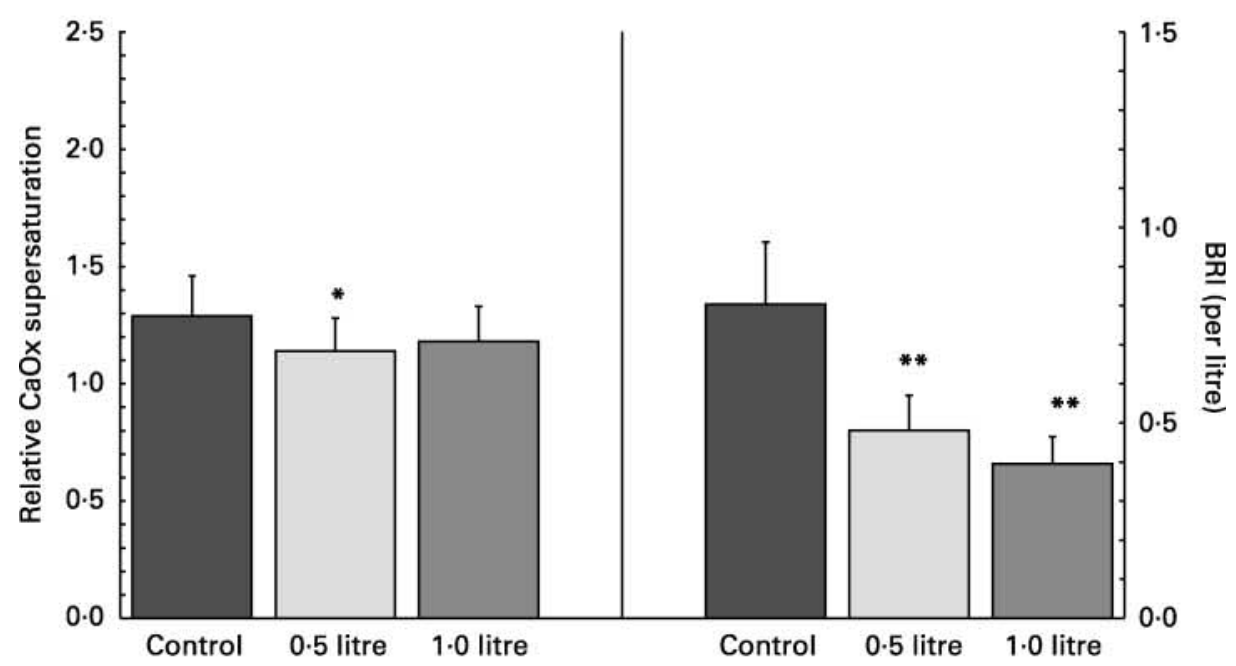

(c)

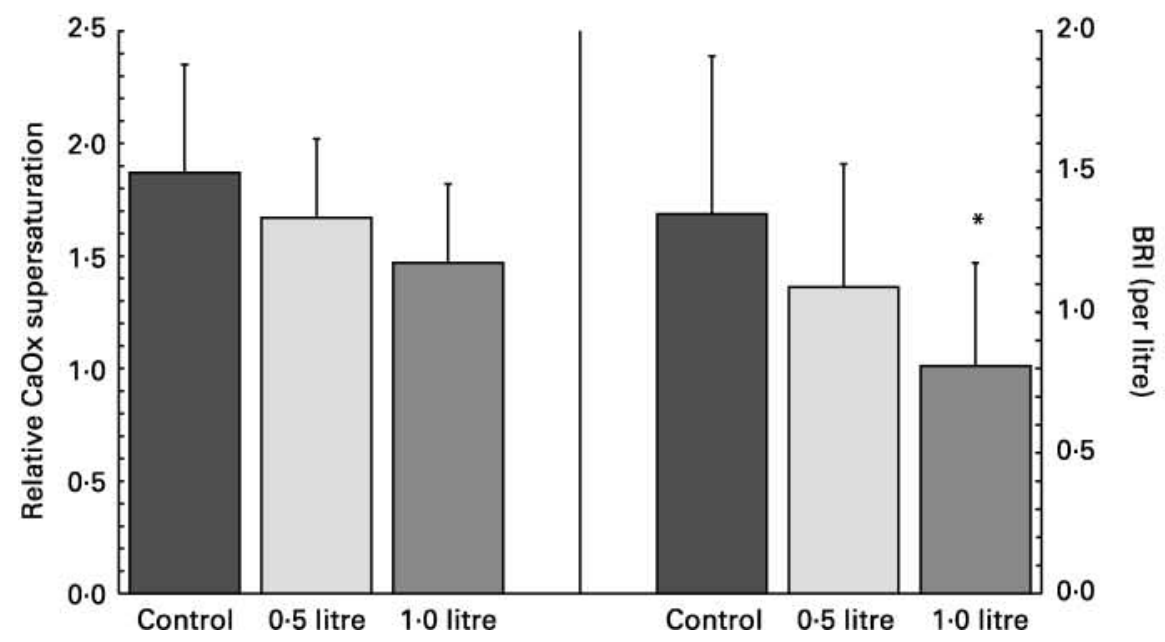

Fig. 2. Effect of orange juice (a), grapefruit juice (b) or apple juice (c) on urine relative supersaturation with calcium oxalate (Ox) and BONN risk index (Laube et al. 2000, 2001). For details of fruit juices, subjects and procedures, see Table 1 and pp. 295-296. Values are means with their standard errors shown by vertical bars $(n 9)$. Mean values were significantly different from those of the control: ${ }^{*} P<0.05,{ }^{* \star} P<0.01$. 


\section{Conclusions}

Analysis of urinary composition and the BRI yielded a distinct decrease in the risk of $\mathrm{CaOx}$ crystallization. Therefore, we suggest that there is no component of grapefruit juice responsible for an increasing risk of stone formation. It can be supposed that women who form stones would react as did those studied here. Thus, we assume that ingestion of grapefruit juice, orange juice and apple juice are effective measures in metaphylaxis of $\mathrm{CaOx}$-stone disease. However, further research on the stone-former is needed to confirm these findings; subsequent studies are necessary to explain which substances of grapefruit juice lead to results described by Curhan et al. (1996, 1998).

\section{References}

Ameer B \& Weintraub RA (1997) Drug interaction with grapefruit juice. Clin Pharmacokinet 33, 102-121.

Curhan GC, Willett WC, Rimm EB, Spiegelman D \& Stampfer MJ (1996) Prospective study of beverage use and the risk of kidney stones. Am J Epidemiol 143, 240-247.

Curhan GC, Willett WC, Speizer PE \& Stampfer MJ (1998) Beverage use and risk for kidney stones in women. Ann Int Med 128, 534-540.

Deutsche Gesellschaft für Ernährung (1996) Empfehlungen für die Nährstoffzufuhr (Recommendations for Nutrient Intakes). Frankfurt: Deutsche Gesellschaft für Ernährung.

Finlayson B (1977) Calcium stones: some physical and clinical aspects. In Calcium Metabolism in Renal Failure and Nephrolithiasis, pp. 337-382 [DS David, editor]. New York, London, Sydney, Toronto: J Wiley \& Sons.

Fuhr U \& Kummert AL (1995) The fate of naringin in humans: a key to grapefruit juice-drug interactions? Clin Pharm Ther 58, 365-373.

Goldfarb DS \& Asplin JR (2000) Effect of grapefruit on urinary lithogenicity. In Urolithiasis, pp. 317-318 [AL Rodgers, BE Hibbert, B Hess, SR Khan and GM Preminger, editors]. Cape Town: University of Cape Town.

Goldfarb DS \& Asplin JR (2001) Effect of grapefruit juice on urinary lithogenicity. J Urol 166, 263-267.

Goldfarb DS \& Coe FL (1999) Beverages, diet, and prevention of kidney stones. Am J Kidney Dis 33, 398-403.

Hesse A \& Bach D (1982) Harnsteine, pathochemie und klinische-chemische diagnostik (Urinary stones, pathochemistry and clinical chemical diagnostics). In Klinische Chemie und Einzeldarstellung $V$ (Clinical Chemistry and Single Cases), pp. 33-38 [H Breuer, H Büttner and D Stamm, editors]. Stuttgart, New York: Georg Thieme Verlag.

Hesse A \& Siener R (1997) Current aspects of epidemiology and nutrition in urinary stone disease. World J Urol 15, $165-171$.

Hesse A, Siener R, Heynck H \& Jahnen A (1993) The influence of dietary factors on the risk of urinary stone formation. Scanning Microsc 7, 1110-1128.

Hesse A, Tiselius HG \& Jahnen A (1997) Urinary Stones, Diagnosis, Treatment and Prevention of Recurrence. Basel, Freiburg, Paris, London, New York, New Dehli, Bangkok, Singapore, Tokyo, Sydney: Karger.

Hönow R, Bongartz D \& Hesse A (1997) An improved HPLC-enzyme-reactor method for the determination of oxalic acid in complex matrices. Clin Chim Acta 261, 131-139.

Laube N, Hergarten S \& Hesse A (2001) Testing the predictability of the relative urinary supersaturation from the BONN-Risk-Index for calcium-oxalate stone formation. Clin Chem Lab Med 39, 966-969.

Laube N, Hergarten S \& Hesse A (2002) Comparison of laser-probe and photometer-based determinations of the urinary crystallization risk of calcium oxalate. Clin Chem Lab Med 40, 595-599.

Laube N, Schneider A \& Hesse A (2000) A new approach to calculate the risk of calcium oxalate crystallization from unprepared native urine. Urol Res 28, 274-280.

Nicar MJ, Hill K \& Pak CYC (1983) A simple technique for assessing the propensity for crystallization of calcium oxalate and brushite in urine from the increment in oxalate or calcium necessary to elicit precipitation. Metabolism 32, 906.

Trinchieri A, Lizzano R, Bernardini P, et al. (2002) Effect of acute load of grapefruit juice on urinary excretion of citrate and urinary risk factors for renal stone formation. Dig Liv Dis 34, pp. 160-161.

Vahlensieck W (1986) Review: The importance of diet in urinary stones. Urol Res 14, 283-288.

Wabner CL \& Pak CYC (1993) Effect of orange juice consumption on urinary stone risk factors. J Urol 149, 1405-1408.

Weber A, Jager R, Borner A, et al. (1996) Can grapefruit juice influence ethinylestradiol bioavailability? Contraception 53, 41-47.

Werness PG, Brown CM, Smith LH \& Finlayson B (1985) Equil 2: A basic computer program for the calculation of urinary saturation. J Urol 134, 1242-1244. 